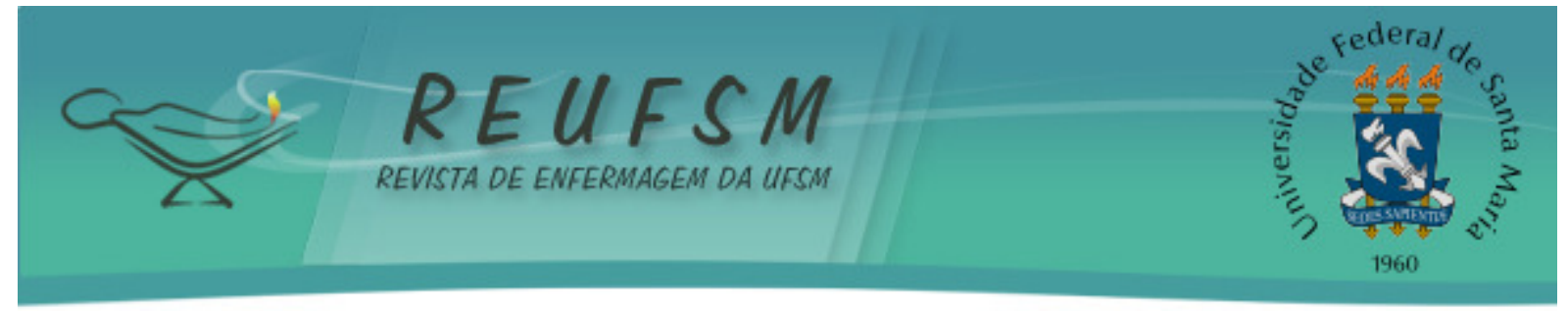

ARTIGO ORIGINAL

\title{
PERCEPÇÃO DE PUÉRPERAS SOBRE A ASSISTÊNCIA À SAÚDE EM UM CENTRO DE PARTO NORMAL
}

\section{PERCEPTION OF POSTPARTUM WOMEN ON THE ASSISTANCE BY HEALTH-CARE IN A NATURAL CHILDBIRTH CENTER}

\section{PERCEPCIÓN DE MADRES SOBRE LA ATENCIÓN EN UN CENTRO DE PARTO NORMAL}

José Francisco Ribeiro ${ }^{1}$ Marisa Ribeiro Lima²

Samia Vanessa Cunha ${ }^{3}$

Vera Lúcia Evangelista de Sousa Luz $^{4}$

Danieli Maria Matias Coêlho ${ }^{5}$

Verbenia Cipriano Feitosa ${ }^{6}$

Doi: $10.5902 / 2179769214471$ Jaqueline Carvalho e Silva Sales ${ }^{7}$

RESUMO: Objetivo: descrever e discutir a percepção de puérperas sobre a assistência da equipe de saúde no Centro de Parto Normal (CPN). Método: pesquisa descritiva com abordagem qualitativa, desenvolvida com 18 puérperas, internadas em uma maternidade pública estadual em Teresina-PI. Dados coletados através de entrevistas, com roteiro semiestruturado nos meses de abril a maio de 2014. Os dados foram submetidos à análise de conteúdo temática. Resultados: emergiram duas categorias: conhecimento de puérperas sobre o CPN e percepção de puérperas sobre o cuidado ofertado pela equipe de saúde no CPN. Conclusões: o estudo poderá contribuir com informações para os profissionais de saúde, em especial para o enfermeiro, sobre a necessidade e importância da realização de orientações à mulher quanto ao parto normal e sobre a existência e funcionamento do CPN, bem como com perspectivas de construção de novas propostas envolvendo equipe e instituição pública de saúde.

Descritores: Saúde da mulher; Parto normal; Período pós-parto; Assistência à saúde; Enfermagem.

ABSTRACT: Aim: to describe and discuss the perception of postpartum women about the health care team in a Natural Birth Center (NBC). Methods: descriptive study with a qualitative approach, developed with 18 puerperal women hospitalized in a public state hospital in Teresina-PI. Data collected through interviews with semi-structured script, from April to May 2014. Data was submitted to thematic content analysis. Results: two categories emerged : mothers' knowledge about the NBC and mothers' perception of the

\footnotetext{
${ }^{1}$ Enfermeiro. Mestre em Ciências da Saúde. Docente da Faculdade Estácio/CEUT. Teresina (PI), Brasil. E-mail: jotafribeiro@hotmail.com

2 Enfermeira. Graduada em Enfermagem pela Faculdade Estácio/CEUT. Teresina (PI), Brasil. E-mail: marisaribeiro@hotmail.com

3 Enfermeira.Graduada em Enfermagem pela Faculdade Estácio/CEUT. Teresina (PI), Brasil. E-mail: samia_vanessa@hotmail.com

${ }^{4}$ Enfermeira.Especialista Materno-Infantil e em Saúde Pública. Docente da Faculdade Estácio/CEUT. Teresina (PI), Brasil. E-mail: vera.lucialuz@hotmail.com

5 Enfermeira.Mestre em Ciências da Saúde. Coordenadora da Graduação em Enfermagem da Faculdade Estácio/CEUT.Teresina (PI), Brasil. E-mail: danielibrisa@hotmail.com

${ }^{6}$ Enfermeira.Mestre em Ciências da Saúde. Docente da Faculdade Estácio/CEUT.Teresina (PI), Brasil. E-mail: verbeniafeitosa@gmail.com

7 Enfermeira. Doutoranda em Enfermagem pela Universidade Federal do Piauí (UFPI). Docente da UFPI. Teresina (PI), Brasil. E-mail: jaqueline-carvalho@uol.com.br
} 


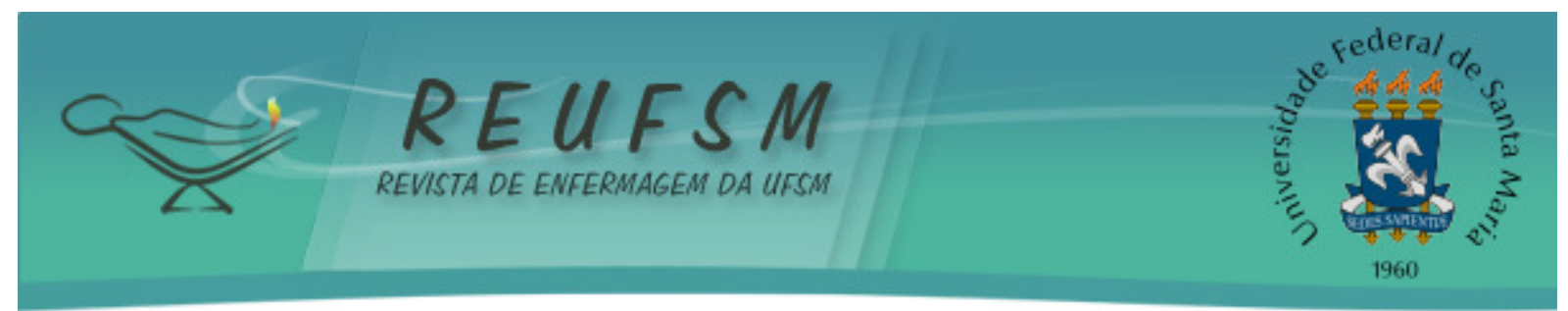

care offered by the health team in the NBC. Conclusions: the study will contribute to health professionals' knowledge on the subject, particularly for male nurses, on the need and importance of carrying out guidance to women concerning normal childbirth and on the existence and functioning of the NBC, as well as the construction of new proposals involving health staff and public health institution.

Descriptors: Women's health; Natural childbirth; Postpartum period; Delivery of health care; Nursing.

RESUMEN: Objetivo: analizar y describir la percepción de las madres sobre el equipo de atención médica de un Centro de Parto Normal (CPN). Métodos: estudio descriptivo de enfoque cualitativo, desarrollado con 18 puérperas hospitalizadas en un hospital público estadual en Teresina-PI. Los datos recogidos a través de entrevistas semiestructuradas, de abril a mayo de 2014, y fueron sometidos a un análisis de contenido temático. Resultados: Dos categorías emergieron: conocimiento de las madres sobre el CPN y percepción de las madres sobre la atención ofrecida por el equipo de salud en el CPN.Conclusiones:el estudio podrá ayudar con informaciones para los profesionales de enfermaría sobre la necesidad e importancia de la orientación a la mujer para el parto normal y en la existencia y funcionamiento de la CPN, así como las perspectivas de construcción de nuevas propuestas de salud relacionadas con el personal de salud y la institución de salud pública.

Descriptores: Salud de la mujer; Parto normal; Periodo posparto; Prestación de atención de salud; Enfermería.

\section{INTRODUÇÃO}

O processo de nascimento é um evento natural, de caráter íntimo e privado, além de uma experiência compartilhada entre as mulheres e seus familiares. Durante muito tempo, parteiras, curandeiros ou comadres eram os responsáveis pela atividade de partejar, por serem pessoas reconhecidas na comunidade ou de confiança das parturientes. ${ }^{1}$

Com o passar do tempo, o parto tornou-se um ato hospitalar, promovido por intensa medicalização e rotinas cirúrgicas, afastando a parteira da arte de partejar e reduzindo o protagonismo da mulher durante o parto. A partir de então a parturiente, no Brasil, passou a ser afastada de seus familiares durante o processo de parturição, permanecendo isolada em uma sala de pré-parto, com pouca ou nenhuma privacidade. ${ }^{2}$

Os profissionais de saúde que atuam nas maternidades possuem forte poder de decisão sobre a vida da mulher, do bebê e da família, passando a controlar quando e como será o parto, e quem e quando se pode ter contato com o binômio mãe e filho. Essas práticas tornaram a assistência ao parto desumanizada, fazendo emergir reflexões sobre a qualidade da atenção prestada a este grupo populacional. ${ }^{3}$

Considerando isso, o trabalho de parto pode ser percebido pela mulher como angustiante, uma vez que a partir do momento em que a mesma é internada na maternidade, passa a não ter controle da situação e tudo se torna imprevisível e nãofamiliar. Deste modo, a parturiente necessita de aproximação e compreensão da equipe de saúde em geral e do enfermeiro em particular. ${ }^{4}$

Nesse sentido, é imprescindível que a equipe de saúde ofereça à mulher informações claras e completas sobre cuidado a ser ofertado no serviço de saúde oportunizando sua participação e tomada de decisão durante todo o processo parturitivo.Ressalta-se que a tomada de decisão depende, também, de conhecimentos e experiências prévias, valores, crenças, medos, anseios e informações obtidas anteriormente. ${ }^{5}$ 


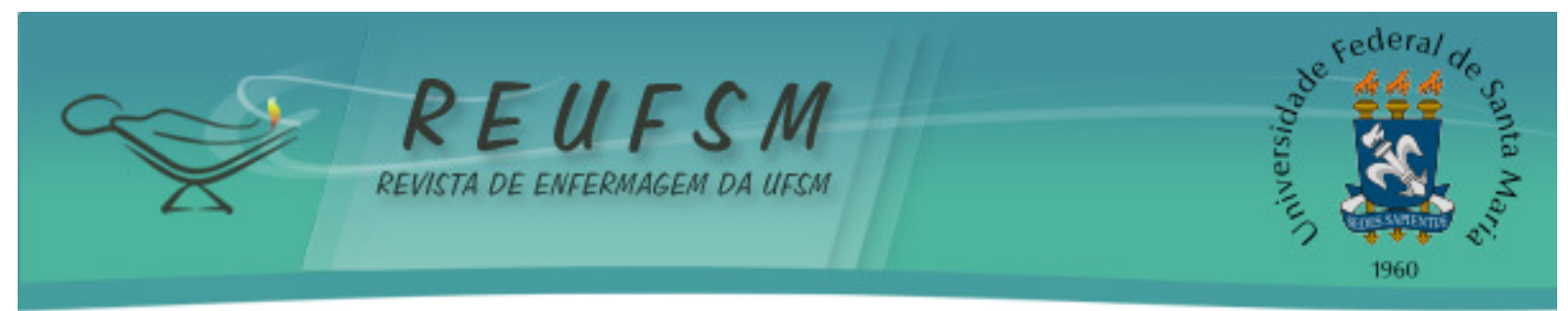

O período que antecede ao processo parturitivo é caracterizado por incertezas, pelo enfrentamento de situações desconhecidas, provocando sentimentos de insegurança e estresse que poderão influenciar também na escolha do tipo de parto. Com o passar do tempo, as decisões sobre o tipo de parto passaram a ser influenciadas pelos profissionais médicos e também pelas expectativas das gestantes, em especial pelo medo da dor e dos riscos que acreditavam estar envolvidos neste período. ${ }^{6}$

À luz desses conhecimentos, destaca-se a criação do Centro de Parto Normal (CPN), que tem como objetivo resgatar o direito da mulher a ter o seu parto em um local semelhante ao seu ambiente familiar, além de proporcionar segurança à mãe e ao seu filho. A implantação deste centro possibilita uma assistência humanizada, onde a mulher tem total autonomia para expressar seus sentimentos e decidir, junto à equipe, qual a melhor conduta a se tomar durante o trabalho de parto e parto. ${ }^{7}$

Acrescenta-se, ainda, que o CPN é uma unidade que tem como finalidade o atendimento de qualidade e exclusivo ao parto normal, atuando no sentido de ampliar o acesso e melhorar o cuidado. Este local deve ser estruturado para oferecer à mulher, bemestar, conforto e segurança. Com o objetivo de aliviar a dor durante o trabalho de parto e para aumentar o relaxamento, são utilizados alguns recursos nesses centros, quais sejam: banhos de banheira e chuveiro, massagens e caminhadas. ${ }^{8}$

O CPN possibilita a adoção de um modelo menos intervencionista, considerando o parto um processo natural e fisiológico. A assistência neste local é focada na mulher, na sua família e em suas necessidades biológicas, psicológicas e sociais. ${ }^{9}$

A assistência de qualidade à mulher em trabalho de parto é um direito fundamental e representa um passo indispensável para garantir que ela possa exercer a maternidade com segurança e bem-estar. A equipe de saúde necessita estar preparada para acolher a parturiente, seu companheiro e demais familiares, respeitando todos os significados desse momento, proporcionando a criação de vínculos, transmitindo-lhe confiança, tranquilidade e garantindo os direitos das mulheres nas ações de saúde. ${ }^{10}$

Nesse contexto, surgiu o interesse em realizar esse estudo para que se perceba como essas mulheres estão reconhecendo a assistência prestada pela equipe de saúde durante o trabalho de parto em um CPN. Para tanto, estabeleceu-se como questão de pesquisa: "qual a percepção das puérperas sobre a assistência prestada pela equipe de saúde em um CPN?". Na tentativa de responder a esse questionamento objetivou-se descrever e discutir a percepção de puérperas sobre a assistência prestada pela equipe de saúde em Centro de Parto Normal.

\section{MÉTODO}

Trata-se de um estudo descritivo com abordagem qualitativa, desenvolvido em uma maternidade pública estadual da cidade de Teresina-PI. Esta instituição é referência para o atendimento de mulheres que apresentam gravidez de alto risco, recebe gestantes provenientes de outros municípios do estado do Piauí em situação ou condição de alto risco, bem como possui um Centro de Parto Normal.

Elegeu-se como critério de inclusão ter idade acima de 18 anos, estar no puerpério mediato no momento da coleta de dados e que após convite individual aceitaram voluntariamente participar da pesquisa mediante a leitura e assinatura do Termo de Consentimento Livre e Esclarecido (TCLE).

A técnica de coleta de dados utilizada neste estudo foi a entrevista caracterizada como um momento que envolve duas pessoas numa situação "face a face" em que uma delas formula questões e a outra responde. A entrevista não é dirigida a uma categoria específica de indivíduos, mas aos que se relacionam com o fenômeno a ser pesquisado. ${ }^{11}$ 


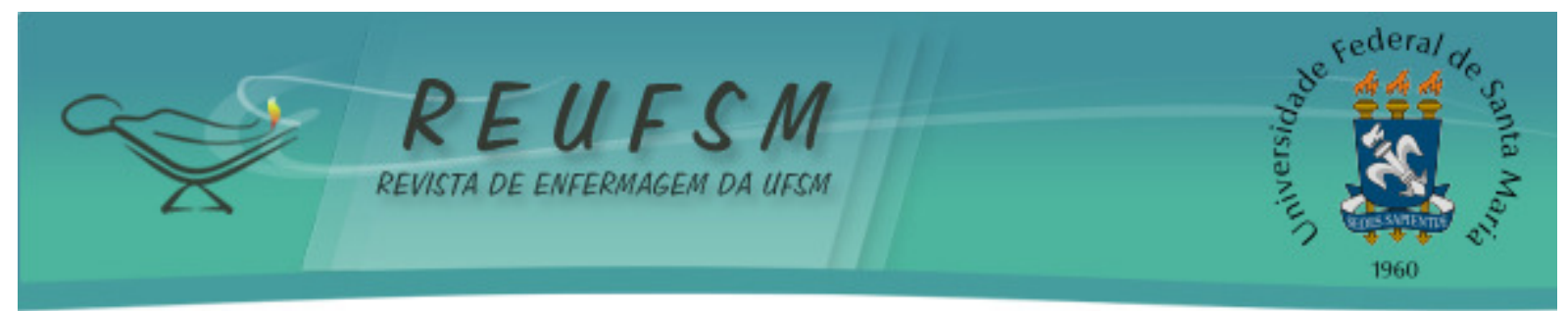

0 instrumento para coleta de dados foi elaborado pelos pesquisadores, constituindo-se em um roteiro de entrevista semiestruturado, que continha perguntas abertas relacionadas à percepção das puérperas sobre a assistência à sua saúde em um CPN e fechadas (idade, cor/raça, estado civil, procedência, escolaridade e número de gestações). Neste tipo de instrumento os participantes da pesquisa podem falar livremente sobre o tema abordado, não se prendendo ao questionamento formulado. ${ }^{12}$

A coleta de dados foi realizada no período de abril a maio de 2014. As entrevistas foram gravadas em MP3 com a permissão das entrevistadas conforme a assinatura no TCLE e os dados foram transcritos e analisados. Assim, após convite individual e aceite voluntário, participaram do estudo 18 puérperas.

Destaca-se que as entrevistas foram encerradas quando ocorreu a saturação dos dados, ou seja, considerou-se não só a repetição dos significados como, também, a singularidade das vivências, pois se tratando de uma pesquisa com abordagem qualitativa esse é considerado um critério para garantir representatividade,possibilitando abranger a totalidade do problema investigado em suas múltiplas dimensões. ${ }^{12}$

Os dados desse estudo foram analisados por meio da técnica de análise temática, uma modalidade da análise de conteúdo. As fases da análise temática compreendem a préanálise, que consiste em leitura flutuante do material para compreensão e para se obter uma visão de conjunto; a exploração do material, que corresponde a uma fase longa com vistas a explorar o material, ou seja distribui trechos, frases ou fragmentos do texto de análise para extrair os núcleos de sentido e o tratamento dos resultados/inferência/interpretação, que objetiva tornar os dados válidos e significativos, atribuindo-se um grau de significação aos conteúdos analisados. ${ }^{12}$

Esta pesquisa seguiu as normas e diretrizes da Resolução 466/2012, do Conselho Nacional de Saúde, por meio do qual foram resguardados os interesses dos participantes envolvidos. ${ }^{13} \mathrm{O}$ projeto foi encaminhado ao Comitê de Ética em Pesquisa do Hospital São Marcos e autorizado em 03 de abril de 2014 conforme CAAE: 26189813.2.0000.5584. 0 anonimato do nome original dos participantes foi garantido através da sua substituição por depoentes e ordenados por uma sequência numérica.

\section{RESULTADOS E DISCUSSÕES}

As idades das puérperas participantes do estudo variaram entre 18 e 44 anos. Destas, dez auto declararam-se de cor parda, três de cor branca, três negras e duas amarelas. Quanto ao estado civil, sete eram solteiras e onze eram casadas/união estável. Quanto à moradia, nove residiam no interior do Piauí, sete em Teresina e duas eram procedentes de uma cidade do estado do Maranhão (Timon). Com relação à escolaridade, oito tinham o ensino fundamental, sete concluíram o ensino médio, duas tinham o ensino fundamental incompleto e apenas uma tinha nível superior. Quanto ao número de gestações, sete eram primíparas e onze multíparas.

Após a análise dos dados foi possível à formulação das seguintes categorias: "conhecimento das puérperas sobre o Centro de Parto Normal" e "percepção das puérperas sobre o cuidado ofertado pela equipe de saúde no Centro de Parto Normal”.

\section{Conhecimento de puérperas sobre o Centro de Parto Normal}

Essa categoria aborda o conhecimento de puérperas em relação ao CPN, fato ilustrado nos depoimentos a seguir: 


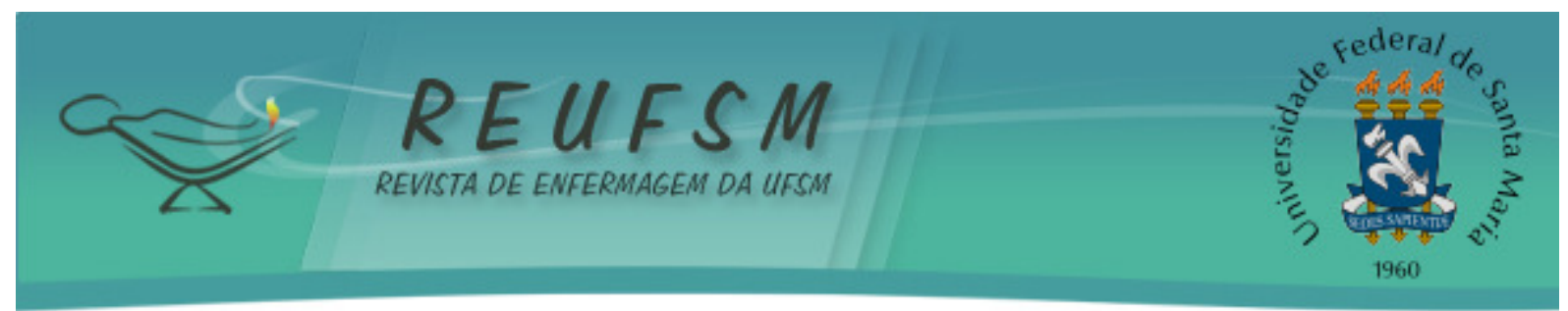

Não sei o que é centro de parto normal. E pelo o que eu pude ver parece ser melhor que os cesarianos, ficaram ao meu lado até ganhar o neném. (Depoente 01)

Não conheço. Gostei muito, agora melhorou bastante foi melhor essa segunda vez. (Depoente 03)

Eu por enquanto não conheço nada, foi a primeira vez e ninguém nunca me falou o que era. (Depoente 04)

Nunca me falaram o que era esse centro de parto normal. [...] eu acho que é a sala que agente fica pra ter o bebê. Para falar a verdade eu vi ontem, mas pelo visto é bom porque as mulheres que fizeram o exercício rápido tiveram. Eu não quis fazer o exercício por vergonha e aí demorei a ter o bebê. (Depoente 05)

[...] é o lugar que as mães vão pra ter seus filhos de parto normal onde agente fica esperando [...]. (Depoente 09)

É aonde agente vai pra ter o bebê normal. Não sei nunca ninguém falou para mim. (Depoente 12)

Através das falas acima foi possível identificar a falta de informação das puérperas em relação ao CPN, reconhecendo-o apenas como uma sala de espera para o parto. Observou-se, ainda, que embora estas mulheres não soubessem o que era o CPN, reconheceram-no como um ambiente positivo na hora do parto.

A partir dos depoimentos, observa-se a importância do atendimento de pré-natal, pois nesse momento a gestante pode ser orientada sobre vários temas, dentre eles: o trabalho de parto e parto, esclarecendo suas dúvidas, medos, angústias. Durante as consultas deve-se realizar um convite à gestante para que a mesma possa conhecer a maternidade em que irá dar à luz, bem como orientá-la sobre o CPN. Salienta-se que a expectativa das gestantes quanto ao tipo de parto está relacionada à maneira como as informações sobre o assunto foram repassadas, pois a qualidade destas orientações funcionam como um instrumento educativo de potencialidade e promotor da saúde. ${ }^{8}$

0 atendimento à mulher necessita ser individualizado e flexível, com apoio emocional, contínuo e fazendo com que a mesma se sinta acolhida e compreendida. Assim, os resultados positivos desta assistência são observados devido à maior motivação da parturiente para um parto sem intervencionismo. ${ }^{9}$

Esta categoria revelou a falta de conhecimento e de orientações com relação ao CPN, informações estas que poderiam ter sido repassadas ainda durante o pré-natal e reforçadas na maternidade durante a sua assistência. Assim, se faz necessário que os profissionais da equipe de saúde reconheçam a importância e funcionalidade dos CPN para que possam orientar estas mulheres durante o acompanhamento e para que as lacunas de falta de informação deixadas no pré-natal possam ser preenchidas na maternidade no momento da internação. 




Percepção de puérperas sobre o cuidado ofertado pela equipe de saúde no Centro de Parto Normal

No processo de cuidar no CPN, as atividades dos profissionais são desenvolvidas para a parturiente e, juntamente, com ela. Para tanto, se faz necessário conhecimento científico, habilidade, intuição, pensamento crítico e criatividade. Nesse sentido, cuidado significa estar próximo da pessoa cuidada, respeitando suas particularidades e privacidade, sendo, portanto, imprescindível o diálogo, sensibilidade, afetividade, o prazer de estar com o outro e a atenção ao bem-estar físico, mental, social e espiritual. ${ }^{14-15}$

Esta categoria demonstra a percepção das puérperas sobre as práticas de cuidado no CPN conforme apresentado nos depoimentos abaixo:

[...] Tem exercício que agente faz com a bola que antigamente não tinha, ficava só na cama deitada esperando a hora, sentindo dor, agora não, agente fica fazendo exercício, está muito melhor agora. (Depoente 06)

Tive muita massagem, conselhos para mãe e também orientação sobre o parto, achei muito importante. Fizeram exercício lá usando uma bola e me botaram para caminhar, não fiz o cavalinho porque já estava bem na hora do neném nascer [...]. (Depoente 10)

Foi bom, ótimo, me botaram para fazer os exercícios com a bola, caminhando, gostei dos exercícios porque facilitou mais e foi rápido na hora do parto. (Depoente 13)

[...] Fiz vários exercícios, eles me ajudaram, me explicaram e depois dos exercícios foi mais rápido ter o bebê. (Depoente 15)

No meu parto eu fiz exercício sentada na bola e, realmente, é muito melhor, agente se sente muito mais a vontade. (Depoente 18)

Observa-se nos depoimentos que as caminhadas, as massagens e os exercícios com a bola foram considerados pelas puérperas como fundamentais para auxiliar e facilitar o trabalho de parto. Nessa perspectiva, os cuidados realizados pela equipe de saúde junto à mulher no ciclo gravídico puerperal envolvem as práticas, procedimentos e conhecimentos utilizados pela equipe durante todo o processo de cuidado. Essas práticas podem promover o conforto e o relaxamento e instituir cuidados eficazes, benéficos e apropriados às necessidades da mulher. ${ }^{16}$

Com a realização dos exercícios no CPN, as mulheres adquirem o poder de sujeitos capazes de escolher e decidir as práticas de cuidado em conjunto com a equipe de saúde. Deste modo, a equipe de saúde estabelece práticas de cuidado humanizado, permitindo assim qualificação da assistência ao nascimento como experiência humana dignificante e prazerosa. Tal fato sinaliza que o CPN possibilita contribuições às ações de qualificação e humanização da assistência obstétrica. ${ }^{16}$

O uso de técnicas e métodos não farmacológicos é uma opção para substituição de anestésicos e analgésicos durante o trabalho de parto e durante o parto. Para isso, faz-se necessário a recomendação de algumas ações, como liberdade de adotar posturas e posições variadas, deambulação, respiração ritmada e ofegante, comandos verbais e relaxamento, banhos de chuveiro e de imersão, toque, massagens e o uso da bola. Estas 


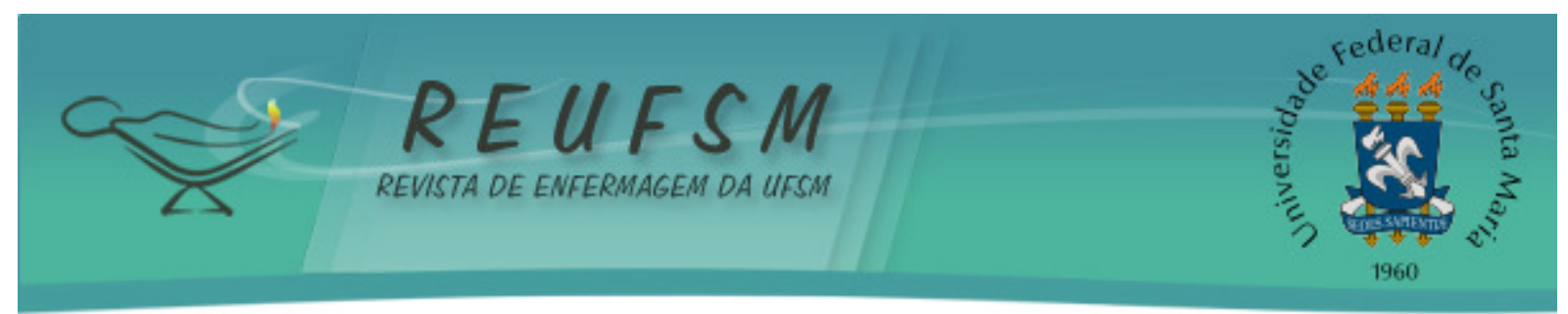

práticas têm a finalidade de tornar o parto o mais natural possível, diminuindo as intervenções, cesarianas desnecessárias e a administração de medicamentos. ${ }^{17}$

Pode-se verificar que a assistência prestada às puérperas no CPN fundamenta-se nos processos fisiológicos e naturais do parto, proporcionando apoio, segurança e condição para a parturiente participar de forma ativa na sua assistência, podendo escolher qual o exercício que quer fazer e o mais confortável que se enquadre a ela no momento. ${ }^{9}$

A assistência ofertada pela equipe durante o trabalho de parto e parto pode influenciar o bem-estar das mulheres e de seus familiares, fazendo com que se sintam mais seguros e amparados. Esta assistência deve atender às necessidades e singularidades das mulheres nesse momento sublime de suas vidas. ${ }^{18}$

Para tanto, a equipe de saúde necessita desenvolver ações com criatividade, senso crítico, capacidade para planejar, organizar, colaborar e avaliar seu resultado, sendo importante que haja respeito, confiança, harmonia, comunicação clara e objetiva, partilha, além de clareza nas tarefas solicitadas e compartilhadas. ${ }^{19}$

Nesta categoria, foi possível verificar que as puérperas apontam em seus depoimentos aspectos positivos relacionados à assistência prestada pela equipe de saúde, como se pode observar nos depoimentos abaixo:

[...] foi muito bom, foi ótimo meu parto e graças a Deus correu tudo bem. Eu fui bem atendida, bem acolhida, foi como se fosse preparada. Me trataram com carinho, não tenho o que reclamar foi muito bom. (Depoente 02)

Me trataram bem, não tenho como falar assim muita coisa [...] na hora que a gente precisa eles estão lá juntos. (Depoente 07)

[...] a equipe que me atendeu teve todo o cuidado, toda a paciência que nem esperava que tivesse comigo, com 44 anos não é fácil pra ter um filho normal, mas eles tiveram paciência comigo todo tempo. (Depoente 08)

Eu gostei que quando cheguei já foi logo me atendendo rapidamente, porque eu estava com muitas contrações, me colocaram logo na cama e eu já tive a neném, eles tomaram os cuidados devidos com ela e já foram logo medicando ela pelo o problema que eu tenho, e até hoje eles me orientam em tudo que eu tenho que fazer. (Depoente 11)

Sobre a equipe de saúde eu não tenho que reclamar nada, eles nos acolheram, são muito bons, atendem a gente bem, prestam atenção em tudo que acontece não deixam a gente sofrer. (Depoente 14)

Cuidaram bem, não me deixaram sozinha. Me acompanharam direitinho, não precisou nem ser cortada, gostei muito. (Depoente 16)

Fui muito bem atendida, tive muita sorte, agradeci demais a eles que foram muito atenciosos desde que cheguei quando estava sentindo dor até a hora do parto. Eles foram muito tranquilos, calmos, muito humanos. (Depoente 17) 


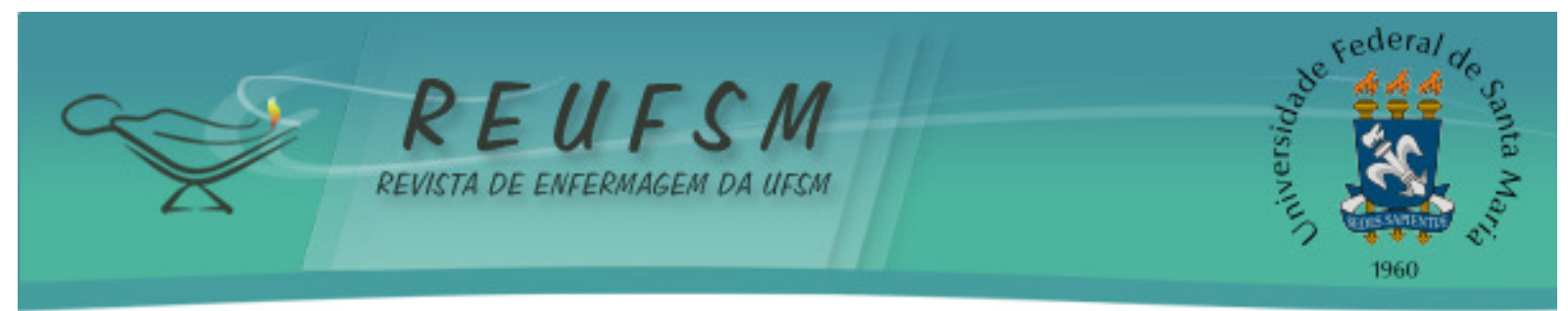

Como visto nos depoimentos, as puérperas reconhecem que a assistência prestada pela equipe no CPN foi de qualidade, pois relatam que foram tratadas com rapidez, atenção, respeito e ainda que não foram deixadas sozinhas. Estas mulheres consideram importantes e valorizam a presença da equipe na sala de parto, devido ao fato de que o acompanhamento, apoio e atividades executadas por esta equipe trouxe segurança, conforto e alívio da dor no trabalho de parto e durante o parto.

A equipe de saúde estabelece uma relação de apoio e atenção para com a mulher desde o momento que antecede até a fase em que se evidencia o parto, tornando possível fazer do processo parturitivo um momento calmo, tranquilo e prazeroso. ${ }^{20}$

Diante disso, pode-se verificar que os cuidados realizados pela equipe e reconhecidos pelas pacientes podem criar um vínculo entre o serviço e o usuário, o que atende a um dos princípios do acolhimento. De acordo com o Ministério da Saúde (MS), o acolhimento como ato ou efeito de acolher expressa, em suas várias definições, uma ação e uma atitude de inclusão. É considerado como um dos recursos importantes para a humanização dos serviços de saúde, não sendo considerado apenas como um espaço e sim com uma postura ética que implica em compartilhamento de saberes, angústias e invenções, tomando para si a responsabilidade de "abrigar e agasalhar". ${ }^{21}$

O cuidado satisfatório é aquele desenvolvido com simpatia, educação, respeito e conhecimentos, constatando assim, uma importância das relações interpessoais e do acolhimento nos serviços de saúde. Essas relações podem viabilizar uma rede de conversações que é essencial ao cuidado, na medida em que contribui com o estabelecimento de negociações entre as necessidades dos usuários e os meios de satisfazê-las. ${ }^{22}$

Portanto, ficou claro que ser tratada com respeito e dignidade, ter os seus direitos reconhecidos e valorizados, sendo bem acolhidas com um atendimento tecnicamente competente que garanta a segurança para elas e seu filho é algo buscado por todas as mulheres entrevistadas, se não por todas as mulheres em geral. Assim, o acolhimento é de vital importância para a qualidade de assistência prestada à mulher, não só no período gestacional como em toda a sua vida.

\section{CONSIDERAÇÕES FINAIS}

Ao entrevistar as puérperas, observou-se a falta de informação das mesmas com relação ao Centro de Parto Normal, reconhecendo-o apenas como uma sala de espera. Entretanto, citaram que caminhadas, massagens e exercícios com a bola são fundamentais para auxiliar e facilitar o trabalho de parto.

0 cuidado ofertado pela equipe de saúde no CPN é reconhecido positivamente pelas puérperas, pois foi evidenciado em suas falas satisfação com a vivência e experiência adquirida no momento do parto, sendo beneficiadas pela utilização de práticas disponíveis nesse local, influenciando o seu bem-estar, fazendo com que se sentissem mais seguras e amparadas.

0 presente estudo demonstra que a percepção de puérperas sobre a assistência à saúde em um CPN poderá contribuir para a assistência a elas prestada, visto que há riqueza de informações nessas falas, o que possibilita melhoria na qualidade da assistência prestada, considerando-se as necessidades e singularidades dessas mulheres.

Espera-se ainda, com esse estudo, contribuir com informações para o meio acadêmico, para os profissionais de saúde, em especial para o enfermeiro, sobre a necessidade e importância da realização de orientações à mulher quanto ao parto normal e também sobre a existência e funcionamento do CPN, bem como com perspectivas de construção de novas propostas de saúde envolvendo equipe de saúde e instituição pública de saúde. 


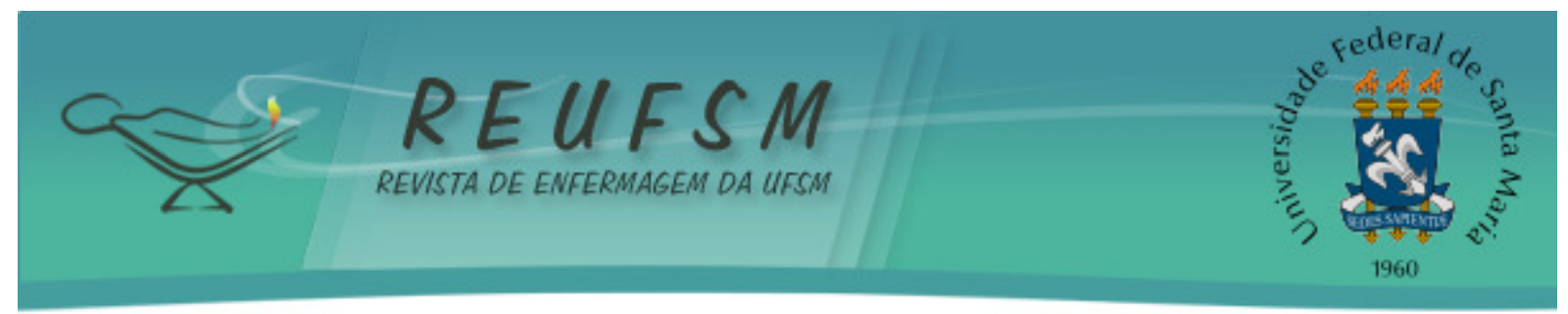

\section{REFERÊNCIAS}

1. Velho MB, Oliveira ME, Santos EKA. Reflexões sobre a assistência de enfermagem prestada à parturiente. RevBrasEnferm.2010;63(4):652-9.

2. Matos GC, EscobalAP, Soares MC, Härter J, GonzalesRIC. A trajetória histórica das políticas de atenção ao parto no Brasil: uma revisão integrativa. RevEnferm UFPE online. 2013;7(N Esp):870-8.

3. Souza TG, Gaíva MAM, Modes PSSA. A humanização do nascimento: percepção dos profissionais desaúde que atuam na atenção ao parto. Rev Gaúcha Enferm.2011;32(3):47986.

4. Carvalho FAM, Oriá MOB,PinheiroAKB,Ximenes LB. Significado do trabalho de parto: aperspectiva dos acadêmicos de enfermagem. Acta Paul Enferm.2009;22(6):767-72.

5. Sodré TM, Bonadio IC, Pinto de Jesus MC, Merighi MAB. Necessidade de cuidado e desejo de participação no Parto de Gestantes Residentes em Londrina-Paraná. Texto \&Contexto Enfermagem.2010;19(3):452-60.

6. Pires D, Fertonani HP, ConillEM, Matos TA, Cordova FP, Mazur CS. A influência da assistência profissional em saúde na escolha do tipo de parto: um olhar sócio antropológico na saúde suplementar brasileira. RevBras Saúde Matern Infantil.2010;10(2):191-7.

7. Machado NXS, Praça NS. Centro de parto normal e assistência obstétrica centrada nas necessidades da parturiente. RevEnfermUSP.2006;40(2):274-9.

8.Brasil. Ministério da Saúde. Secretaria de Atenção à Saúde. Departamento de Ações Programáticas Estratégicas. Gravidez, parto e nascimento com saúde, qualidade de vida e bem-estar. Brasília: Editora do Ministério da Saúde; 2013.

9. Scheidt TR.Assistência das enfermeiras obstétricas nos centros de parto normal (monografia de especialização). Florianópolis: Universidade do Sul de Santa Catarina. 2011. $19 f$.

10.Santos L MS, Pereira SSC. Vivências de mulheres sobre a assistência recebida no processo parturitivo. Physis.2011;22(1):77-97.

11. Gil AC. Como elaborar projetos de pesquisa. São Paulo: Atlas; 2010.

12. MinayoMCS. Pesquisa social: teoria, método e criatividade. Rio de Janeiro: Vozes; 2011.

13. Brasil.Ministério da Saúde. Conselho Nacional de Saúde. Resolução CNS, $n^{\circ} 466$, de 12 de dezembro de 2012. Aprova diretrizes e normas regulamentadoras de pesquisas envolvendoseres humanos. Brasília: Ministério da Saúde; 2012.

14. BalduínoAFA,AntovaniMF, Lacerda, MR. O processo de cuidar de enfermagem ao portador de doença crônica cardíaca. Esc Anna Nery RevEnferm. 2009;13(2):342-51.

15. Rodrigues DP, Silva, RM, Fernandes AFC. Ação interativa enfermeiro-cliente na assistência obstétrica. RevEnferm UERJ. 2006;14(2):232-8.

16.Pereira ALF, Bento AD. Autonomia no parto normal na perspectiva das mulheres atendidas na casa de parto. Rev Rene. 2011;12(3):471-7.

17. Sescato AC, Souza SRRK, Wall ML.Os cuidados não-farmacológicos para alívio da dor no trabalho de parto: orientações da equipe de enfermagem. CogitareEnferm. 2008;13(4):58590. 


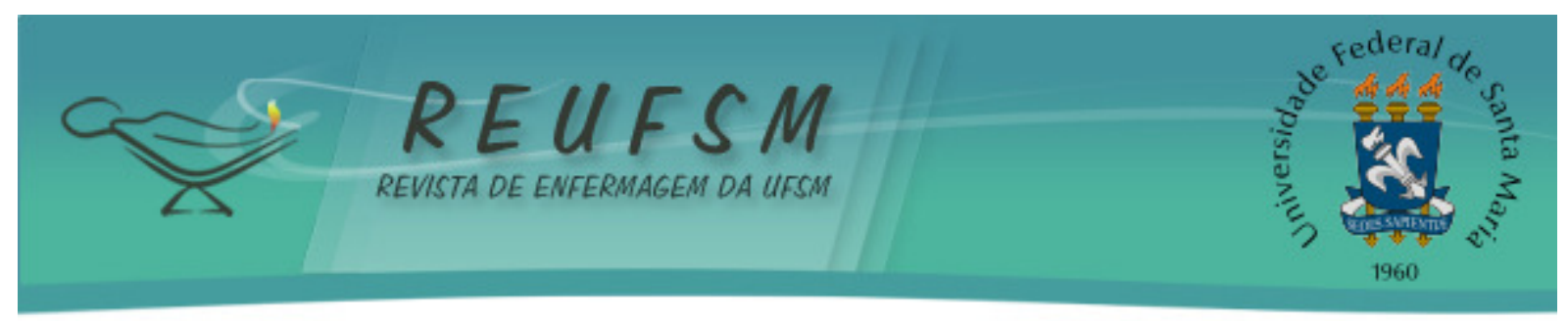

18. Fialho TC. O papel do enfermeiro no parto humanizado (monografia de especialização). Viçosa (MG): EVATA- Educação Avançada LTDA; 2008.38 p.

19. Geus LMM, Maciel CS, Burda ICA, Daros SJ, Batistel S, Martins TCA,et al. A importância na Inserção da Nutricionista na Estratégia Saúde da Família. Ciênc Saúde Coletiva.2011;16Supl1:797-804.

20. Santos LM, Carneiro CS, Carvalho ESS, Paiva MS. Percepção da equipe de saúde sobre a presença do acompanhante no processo parturitivo. Rev Rene. 2012;15(5):994-1003.

21. Brasil. Ministério da Saúde. Secretaria de Atenção à Saúde. Núcleo Técnico da Política Nacional de Humanização.Acolhimento nas práticas de produção de saúde. Brasília: Editora do Ministério da Saúde; 2010.

22. Parada CMGL, ToneteVLP. O cuidado em saúde no ciclo gravídico-puerperalsob a perspectiva de usuárias de serviços públicos. Interface (Botucatu).2008;12(24):35-46.

Data de recebimento: $21 / 06 / 2014$

Data de aceite: 15/09/2015

Nome: Vera Lúcia Evangelista de Sousa Luz

Contato do autor responsável: (086) 3234-5504, (086) 99921-3485

Endereço postal: Rua Marte $\mathrm{n}^{\circ}$ 4280, Bairro Satélite, CEP 64056-700, Teresina (PI), Brasil.

E-mail: vera.lucialuz@hotmail.com 